\title{
Florestan: um sociólogo comprometido com seu tempo
}

\author{
BOAVENTURA DE SOUZA SANTOS
}

S

ENHOR REITOR, senhor ministro da Cultura, senhor representante do governo do estado de São Paulo, colegas da mesa e do auditório, senhoras e senhores. Se já me sentia pequeno aqui nesta mesa, ao lado de colegas que conheceram e privaram de perto com o professor Florestan, que se beneficiaram da sua liderança intelectual, do seu companheirismo e cumplicidade política, mais pequeno me sinto agora, eu que venho de outro país, depois desta magnifica e fascinante narrativa do professor Antonio Candido.

O facto pelo qual aqui estou deve-se a uma razão menor que, afinal, talvez não seja tão pequena, nomeadamente em termos de lógica das instituições. A minha única legitimidade para estar aqui, é apenas o facto de eu ter tido a honra de ser o padrinho do professor Florestan Fernandes na atribuição do grau de Doutor Honoris Causa pela minha universidade, em 1990.

Numa universidade com 700 anos, o professor Florestan Fernandes foi o primeiro Doutor Honoris Causa em sociologia. Sinto muita honra por estar associado a essa iniciativa de grande simbolismo, na qual está implícita a tentativa de aproximar em novos termos as comunidades científicas do Brasil e de Portugal. Sem esquecer o que de bom e mau houve no nosso passado comum, temos de levar em conta, neste momento, o futuro que está à nossa disposição.

Talvez por isso, apetecia-me agora lembrar um dos ditos conhecidos de Saint Simon. Como sabem, Saint Simon fez vários projectos utópicos de sociedade. Achara que a sociedade do futuro deveria se organizar segundo dois tipos de festas - as festas da lembrança e as festas da esperança. As da lembrança cram festas que a socicdade necessitava para criar os seus ancestros, as suas autoridades, as stus tradiçōes, os séus costumes, e dar-lhes um sentido de rázes. As da esperança, ao contrario, cram festas yuc a socicdade deveria organizar para as now as geraçóes, para lles abrir novos campos, nowos horizontes, novas opçóes e permitir que seguissem so/inhos a marca do seu tempo.

Gostaria de rer esta corimónia, nào como uma festa da lembrança, mas como um. festa da esperança. E acho que, neste caso, para mim, que tice um contacto tardio, mas importante, com o trabalho de Florestan, vale a pena salicntar que a marca de excelència de um sociólogo reside em ele saber ser sociólogo 
dàs suas circunstâncias: saber assumir o seu tempo, assumi-lo criticamente naquilo que ele tem.de emergente e de futurante. Penso que Florestan Fernandes fez isso com audácia, com qualidade, com eloqüência e com brilho inexcedíveis.

É esta assunção das circunstâncias, o saber lê-las e saber tirar delas o futuro, que penso ser o grande legado deixado por Florestan. Legado que não reside tanto nas suas teorias e metodologias, mas no modo como, através dele, aprendemos a ler criticamente - descomprometida mas comprometidamente, isto é, com independência e com objectividade mas sem neutralidade - o nosso tempo, as circunstâncias que nos rodeiam e tão diferentes são daquelas que Florestan viveu. Portanto, essa capacidade de voar que penso que Florestan nos deu é que gostaria muito de salientar aqui.

Se o analisarmos nessa perspectiva, concluiremos naturalmente que em termos metodológicos, nem tudo em Florestan é actual. Se quisermos hoje ser florestanianos, temos de ir contra alguns dos textos de Florestan, sem dúvida muito importantes no momento e no contexto em que foram escritos. E porque foram eles importantes? Penso - e agora, depois de ouvir o professor Antonio Cândido, fiquei perfeitamente seguro dessa minha conviç̧ão - ele quis realmente fundar um discurso novo sobre a sociedade brasileira. Uma nova racionalidade, um novo pensamento, um novo critério científico, que de alguma maneira não fosse o daqueles, a que Carlos Guilherme Mota chamou, recordando um texto do próprio Florestan, "intérpretes falando da varanda". Esta nova racionalidade e este novo rigor são muito importantes como instrumentos de luta contra $o$ pensamento mítico desenvolvido pelas elites sobre as nossas sociedades. Florestan empreendeu esta luta com muito rigor e com muita força.

Para o fazer, Florestan assumiu um critério, uma postura científica e epistemológica, que talvez pudesse hoje se considerar positivista, ainda que não empiricista, isto porque ele mostrou, e o fez muito cedo e de forma notável nos seus textos epistemológicos e teóricos, que há um comando da teoria, mas que essa teoria tem de ser representativa do real, tem de ter o rigor de um modelo científico universal. Florestan acreditava na possibilidade de um modelo científico universal. Acreditamos nós hoje nele? Provavelmente não acreditamos, ou não acreditamos da mesma forma. Vivemos numa outra época, num outro tempo, talvez sejamos mais indisciplinados porque nos confrontamos com outras circunstâncias temporais e históricas nos nossos países e no próprio desenvolvimento científico. Tudo isto, talvez nos obrigue a assumir outra postura epistemológica que, no entanto, tem como fundamento o mesmo apelo que moveu Florestan, ou seja, o de responder às circunstâncias do seu tempo.

Acho que isso é fundamental, sobretudo se ao analisarmos os seus textos tivermos em conta uma dimensão de que se fala muito na sociologia actual: a reflexividade. A teoria sociológica hoje é reflexiva, a modernidade é reflexiva, a 
pós-modernidade é reflexiva. Florestan é, desde os seus primeiros livros, um autor reflexivo. Pelo menos foi assim que eu o li, e admito que os colegas brasileiros o tenham lido de modo distinto. Essa reflexividade vai aumentando nos seus escritos, à medida que vai perdendo o gosto ou ficando desencantado com a possibilidade de, como sociólogo, utilizar a engenharia social para transformar a realidade. Gabriel Cohn, num importante texto sobre Florestan, salientou tal facto quando referiu que o seu problema foi o de querer constituir cientificamente uma sociedade, um conhecimento sobre a sociedade, quando o poder parece tão refractário às idéias científicas. Portanto, essa é a missão que ele cumpre, olhando muito o seu contexto - como também a professora Maria Arminda Arruda, noutro texto importante salientou: "contexto social em que emerge e do qual procura desenvolver um conhecimento novo".

A nossa responsabilidade é responder à nossa circunstância, tal como Florestan respondeu à sua. Com pluralismo, talvez com um pouco mais de tolerância discursiva e com mais interdisciplinaridade, que de alguma maneira ele praticou desde cedo, mas sobre a qual não quis reflectir muito. Hoje encontramonos perante um processo de transdisciplinaridade, talvez porque a sociedade na qual nos localizamos nos apele a isso mesmo. Mas é curioso ver que, de alguma maneira, os fantasmas com os quais ele teve de lutar, os seus inimigos, são ainda hoje os nossos fantasmas e inimigos. Em texto de um curso de férias de 1950, Florestan diz aos estudantes que a sociologia tem de se constituir contra dois viéses: de um lado a cosmologia popular, do outro lado o socialismo. É estranho que ele coloque assim a questão. Segundo ele, o socialismo só muito brevemente teve uma constituição científica. À medida que se transformou em doutrina perdeu essa constituição e Florestan vê a sua tarefa como a de refundar essa cientificidade, com um grau de exigência que não vê qualquer conflito entre, como dizia o professor Antonio Candido, a sociologia convencional, as técnicas de rigor científico e, por outro lado, essa nova abertura a uma militância, digamos assim política, que ele quis também instaurar.

Penso que nós hoje vivemos muito essa circunstância. Ou seja, não podemos ser cientistas sociais sem a exigência de cidadania, e essa foi cada vez maior em Florestan. De alguma maneira podemos dizer que ele talvez não tenha conseguido compatibilizar exactamente a exigência científica com a política. $\mathrm{Ou}$ seja, a política bateu-lhe à porta com demasiada violência para as luvas brancas da ciência e ele teve que responder a soco, teve que responder com muita frontalidade e rigor. Frontalidade e rigor que eram as únicas armas com as quais ele podia lutar contra quem usava golpes baixos para destruir o conhecimento e a tradição democrática que entretanto aqui se ia instituindo.

Penso portanto que, tal como Florestan o fez, é possível se ser, numa sociedade de classes e subdesenvolvida, rigoroso sem ser descomprometido; que 
é possível o entusiasmo e a cidadania, mantendo, no entanto, a lucidez dos instrumentos e quiçá também os limites desses instrumentos. Diz Florestan que "o cientista escrupulosamente 'neutro' pode ser tão revolucionário quanto o cientista abertamente 'comprometido'. Contudo, o primeiro não desenvolve a sensibilidade para os problemas de investigação que se impõem em termos de atualidade ou de necessidade histórica. $O$ segundo, ao contrário, está continuamente imerso no fluxo dos acontecimentos que possuem significado fundamental para a colectividade - tanto na superação do passado, quanto na construção do presente e do futuro".

É exactamente este sociólogo, comprometido com o seu tempo, com o entusiasmo das lutas sociais e com o sofrimento que elas produzem também nas populações, que Florestan, sem perder o sentido dos seus instrumentos, das suas teorias, do conhecimento e dos seus limites, dá uma lição que, para as gerações futuras, é absolutamente impescindível. Naturalmente que ele viveu um tempo diferente do nosso; se ele hoje fundasse uma faculdade, não tenho dúvidas de que o faria de maneira diferente do que fez na sua época. Mas porque? Porque ele trabalha de acordo com a sua metodologia e constitui os seus objectos de pesquisa no momento em que há uma grande coerência entre o modelo organizacional e a metodologia e a tecnologia do conhecimento que estão instauradas. Nesse momento, a sociologia e as ciências sociais têm uma metodologia que de alguma maneira é coerente com a sua organização institucional. Ambas apelam à disciplinaridade, ambas aspiram à contenção de equilíbrios institucional, metodológico e estrutural. Contudo, hoje vivemos em instituições falidas, instituições como as universidades nas quais nós não cabemos, pois o nosso conhecimento extravasa delas, muito mais indisciplinado do que as disciplinas que o procuram conter. Temos de refundar a universidade e o saber e eu penso que só o conseguiremos se soubermos ser sociólogos das nossas circunstâncias tão bem quanto Florestan Fernandes o soube ser das suas.

Boaventura de Souza Santos é diretor do Centro de Estudos Sociais da Faculdade de Economia da Universidade de Coimbra, Portugal.

Transcrição da intervenção oral, revista pelo autor, feita no Ato Presença de Florestan Fernandes, organizado pelo Instituto de Estudos Avançados na Sala do Conselho Universitário da USP em 5 de outubro de 1995. . 


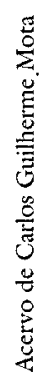

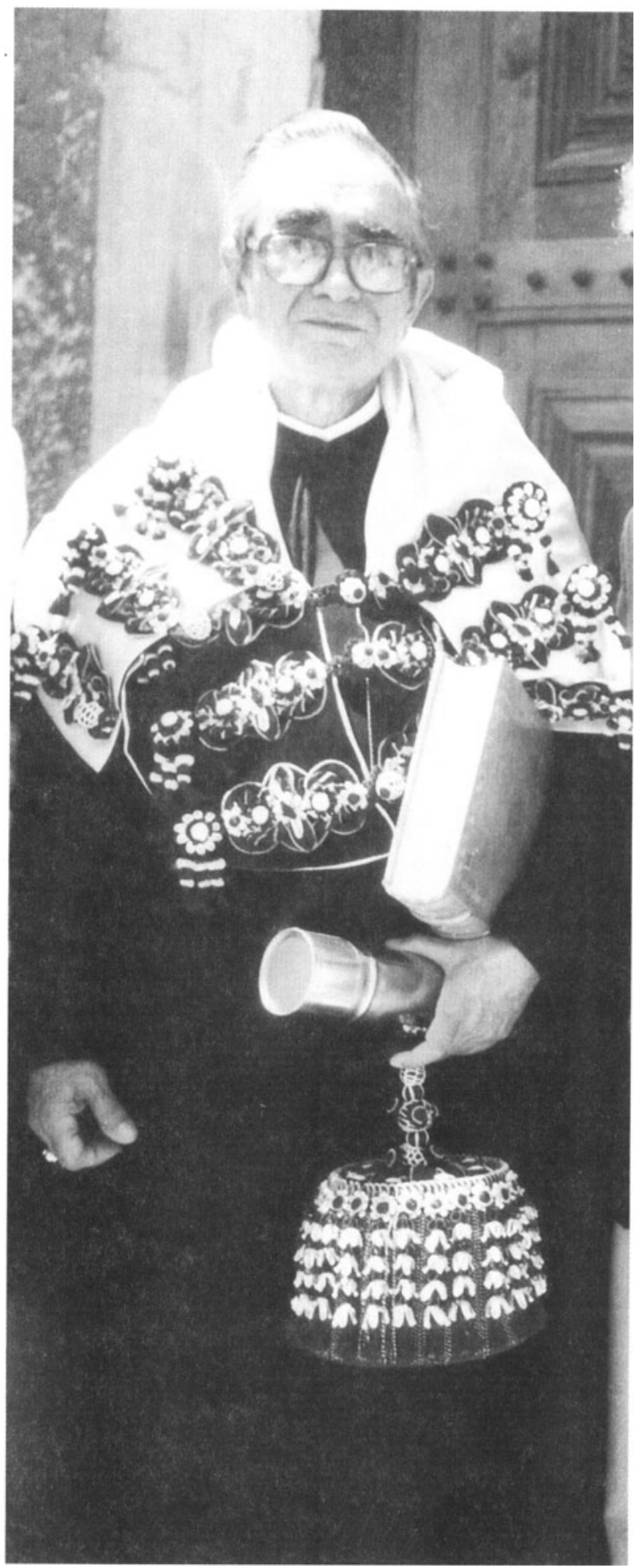

Em 1990, Florestan recebeu o título de Doutor Honoris Causa $\mathrm{cm}$ Sociologia da Universidade de Coimbra 